\title{
Using Structural Equation Modelling to study the influence of perceived usefulness and perceived compatibility on students' attitudes towards using IPAD
}

\author{
Bashar Zogheib \\ American University of Kuwait \\ Salmiya, Kuwait
}

\begin{abstract}
In this research an attempt has been made to test the integration of the Technology Acceptance Model (TAM), user satisfaction, and perceived compatibility in the educational field. It particularly uses Structural Equation Modelling with various constructs to investigate students' acceptance of using IPAD as a technological tool in undergraduate math classes in a Middle Eastern University. The result agrees with the theoretical model, it shows the influence of user satisfaction, perceived usefulness and perceived compatibility on students' attitudes towards using IPAD. Finding of this research along with the ongoing research should encourage educators to put more emphasis on using technology in the learning process of mathematics.
\end{abstract}

Keywords: technology; SEM; satisfaction; mathematics; educators 